\title{
AC 2011-1871: ENRICHING K-12 MATH EDUCATION USING LEGOS
}

\section{Irina Igel, NYU Poly}

IRINA IGEL received the B.S degree in Mathematics with a minor in Computer Science from NYU-Poly, Brooklyn, NY, in 2009. Upon graduating she received an Adjunct Instructor position at the Department of Mathematics at NYU-Poly, teaching undergraduate math courses to incoming freshmen. She is currently serving as a teaching Fellow at the Bedford Academy HS under NYU-Poly's GK-12 program funded by NSF and CBRI consortium of donors. She is perusing the M.S. degree in Mechanical Engineering with emphasis on Control and Dynamical Systems. Her research interests include cooperative control of multi-agent systems, flocking and shoaling behavior in live animals, and distributed consensus algorithms analysis and computation.

\section{Ronald Leonel Poveda, Polytechnic Institute of NYU}

RONALD POVEDA received the B.S. degree in Mechanical Engineering, Summa Cum Laude, from the Polytechnic Institute of NYU, Brooklyn, NY, in 2009. Upon graduation, he started research for a Ph.D. degree in Mechanical Engineering in the Composite Materials and Mechanics Lab (CMML). He is currently serving as a teaching Fellow at the Mott Hall Bridges Academy under NYU-Poly's GK-12 program funded by the NSF and CBRI consortium of donors. In the summer of 2008, he held a mechanical engineering internship position with Motorola, Inc., performing mechanical testing and evaluation of scanners and other mobile devices in Holtsville, N.Y. His largely experimental research is focused on parametric studies of novel lightweight composites and simulations of functionally-graded materials under load.

\section{Vikram Kapila, Polytechnic Institute of New York University}

VIKRAM KAPILA is an Associate Professor of Mechanical Engineering at Polytechnic Institute of NYU, Brooklyn, NY, where he directs an NSF funded Web-Enabled Mechatronics and Process Control Remote Laboratory, an NSF funded Research Experience for Teachers Site in Mechatronics, and an NSF funded GK-12 Fellows project. He has held visiting positions with the Air Force Research Laboratories in Dayton, OH. His research interests are in cooperative control; distributed spacecraft formation control; linear/nonlinear control with applications to robust control, saturation control, and time-delay systems; closed-loop input shaping; spacecraft attitude control; mechatronics; and DSP/PC/microcontroller-based real-time control. Under Research Experience for Teachers Site and GK 12 Fellows programs, funded by the National Science Foundation, and the Central Brooklyn STEM Initiative (CBSI), funded by the Brooklyn Community Foundation, Xerox Foundation, J.P. Morgan Chase Foundation, Motorola Foundation, White Cedar Fund, and NY Space Grant Consortium, among others, he has conducted significant $\mathrm{K}-12$ outreach to integrate engineering concepts in science classrooms and labs of several New York City public schools. He received Polytechnic's 2002 and 2008 Jacobs Excellence in Education Award and 2003 Distinguished Teacher Award. In 2004, he was selected for a three-year term as a Senior Faculty Fellow of NYU-Poly's Othmer Institute for Interdisciplinary Studies. His scholarly activities have included 3 edited books, 4 chapters in edited books, 1 book review, 43 journal articles, and 92 conference papers. Moreover, he has mentored 67 high school students, over $170 \mathrm{~K}-12$ teachers, 21 undergraduate summer interns, and 11 undergraduate capstone-design teams, and graduated eight M.S. and four Ph.D. students.

\section{Magued G. Iskander, Polytechnic Institute of New York University}

MAGUED ISKANDER is Associate Professor and Graduate Adviser of the Civil Engineering Department at Polytechnic Institute of NYU, Brooklyn, NY. Dr. Iskander is a recipient of NSF CAREER award, Chi Epsilon (Civil Engineering Honor Society) Metropolitan District James M. Robbins Excellence in Teaching Award, Polytechnic's Distinguished Teacher Award, and Polytechnic's Jacobs Excellence in Education Award (twice). Dr. Iskander's research interests include Geotechnical modeling with transparent soils, foundation engineering, and urban geotechnology. He makes extensive use of sensors and measurement systems in his research studies. Dr. Iskander has published 10 books, 90 papers and graduated 6 doctoral students, 27 masters students, 12 undergraduate research assistants, and supervised the research activities of 3 school teachers and 9 high school students 


\section{Enriching K-12 Math Education Using LEGOs}

\section{Introduction}

To address mathematical and scientific obstacles of any era, prize-based competitions are frequently organized. Such competitions generate widespread interest and open multiple fronts to advance the state of the art in science and technology. Although this strategy has a long history, it has recently regained currency as evidenced through the Millennium Prize Problems and the Netflix Million Dollar Programming Prize. In a similar vein, a proliferation of competitions, such as Future City, First LEGO League (FLL), etc., are being directed at K-12 students to engage their interest in science, technology, engineering and math (STEM). Participation in the FLL contest provides compelling learning experiences to students and imparts critical academic, professional, and communication skills to them. For example, in a Brandeis University study, ${ }^{1}$ students reported that participation in FLL contests enhanced their interest in science and math and increased their confidence and motivation for school work.

In K-12 math courses, students are required to learn abstract math concepts, e.g., algebra and statistics, as well as problem-solving, graphical interpretation, and measurement methods. The challenge of teaching abstract concepts in the K-12 environment is to get away from lowlevel mechanistic instruction relying on formulae and mnemonics. ${ }^{2}$ Students lose motivation in the face of having to comprehend material that appears to be unrelated to their everyday experiences. ${ }^{3}$ To overcome such obstacles, many mathematics concepts can be viewed as inherent to explaining simple tasks performed by a robot. For example, as students develop strategies for the locomotion of a robot traveling a specified distance, they gain an understanding of the geometry of a circle, which connects the distance traveled by the robot to the circumference of its wheels.

Examples of using robotics to teach STEM concepts abound in literature and cover the entire education spectrum from elementary to graduate school. ${ }^{4-6}$ Unfortunately, the extracurricular nature of robotics contests has not made the use of robotics more central to K-12 science and math education. Moreover, the potential for explicitly exploring science and math

principles using robotics-based activities remains largely untapped in K-12 schools. ${ }^{7}$ Many robotics-focused K-12 programs are organized as outreach efforts for students' educational enrichment and necessitate on-site support of teachers through college-level engineering students $^{5}$ or volunteer engineering professionals, ${ }^{8}$ thereby making it difficult to sustain and scaleup projects. Therefore, increasingly, the focus of educators has been to transition students' extracurricular robotic experiences from the after-school and competition preparation programs to the classroom setting. 
In this paper, we present several illustrative LEGO-based math activities developed by engineering graduate students in partnership with K-12 teachers under an NSF GK-12 Fellows project at the Polytechnic Institute of NYU. These lessons are grade appropriate and address New York State (NYS) math learning standards. For example, one LEGO-based lesson teaches students principles of rounding and accuracy. In this lesson, students operate a robot to draw straight lines of various lengths and ascertain the lengths of drawings with theoretical and ruler measurements. In another lesson, students explore the mathematical constant $\pi$ by operating a robot to draw circles of various diameters. To calculate the value of $\pi$, students measure the circumference of the circle and divide it by the measured diameter of the circle. In yet another lesson, students learn to collect and analyze empirical data from spring-mass oscillations using statistical quantities such as the mean, mode, and median. These lessons were designed to engage students in K-12 math classrooms and allow them to explore abstract math concepts using LEGO-based, hands-on activities. In the following, we provide an overview of these activities, their classroom implementation, assessment, and statistical significance of assessment results.

\section{Objectives and Assessment Methods}

In Sections 3-5, we introduce three illustrative LEGO-based activities that teach math skills and concepts as well as present real-world applications of math to K-12 students. All activities were developed and conducted by the graduate "Fellows" in partnership with teachers at elementary, middle and high schools in Central Brooklyn. The teachers reviewed and approved each lesson for alignment with their curriculum. The objective of the lessons was to teach students abstract math concepts, which are tested in the NYS exams, through fun, engaging, and interactive hands-on LEGO-based activities. Using student-friendly technology and software, the lessons promoted team-oriented and research-like environment. Specific math concepts and skills addressed by the lessons address NYS Learning Standards shown in Tables II, V, VIII. ${ }^{9}$ Detailed lesson plans and corresponding evaluation instruments can be obtained by accessing the GK-12 project website. ${ }^{10}$

The aim of the assessment activities was to measure the effectiveness of the three LEGObased lessons using pre- and post-lesson surveys. The design of specific assessment instruments and their implementation was discussed with a science education expert and the respective grade and subject teachers to be timely, responsive, appropriate, and effective for the intended students. The questions asked in the pre- and post-lesson surveys were designed to determine students' understanding of the lesson topics before and after their engagement in the LEGO-based activities. To assess the effect of lessons on students' comprehension, similar questions were embedded in the pre- and post-lesson surveys. That is, questions designed to elicit students' understanding of various concepts were worded differently in the pre- and post-lesson surveys. For example, to evaluate whether LEGO activities improved students' understanding of applicability of math in their daily lives, students were asked, "Where do you use math outside of 
school?" in pre-survey and "Give an example from your daily life that requires math" in postsurvey. The survey utilized multiple choice questions, fill in the blanks, and short answer essays in a student-friendly format. The questions were designed to test students' conceptual understanding and to determine their interest and attitude toward STEM topics. The responses to survey questions were compiled and analyzed using bar charts and a statistical hypothesis test. Bar charts summarize students' performance before and after the activity. Rubrics shown in Tables III, VI, IX, were used to ascertain the correctness of student responses. Tables III, VI, IX also provide illustrative examples of students' answers to concept and evaluation questions which were marked as correct or incorrect. A dependent $t$-test ${ }^{11}$ for paired samples was conducted to analyze the data and establish whether student performance improved following the activity. To obtain the data for the hypothesis testing, student responses were graded using the rubric in Table I. The pre- and post-lesson scores were matched for each student and analyzed for statistical significance. The results for the test provide the mean difference, standard deviation, $t$-statistics, and $p$ values. For complete results and details of the particular lesson evaluation see the corresponding lesson assessments in Subsection 3.1, 4.1, and 5.1.

Table I: The grading rubric used for the dependent $t$-test for paired samples.

Gives an excellent, thorough, descriptive response involving math terminology

Gives a slight description with object, place, or action

States relevant object or place with no description, few words

States an object or place with little relevance to topic, vague

Gives no answer, incomplete answer, or does not answer proposed question

\section{Lesson on Accuracy and Approximation}

The lesson entitled "About Accuracy and Approximation" introduced elementary school students to the concept of rounding numbers and quantifying accuracy through measurements. The use of a ruler, calculation of values with decimals, numerical estimation, and rounding were integrated in the lesson. The lesson was aimed at teaching students the concept of accuracy, particularly of machines and humans. The lesson addresses NYS Learning Standards for Mathematics shown in the Table II, and requires one to two 45-minute class periods to complete. The following materials were used to conduct the activity: a LEGO NXT robot with a pen holding attachment, a marker, large pieces of white paper, a ruler, yarn, a notepad, and a pen (see Figure 1). 
Table II: NYS Learning Standards addressed in “About Accuracy and Approximation” lesson. ${ }^{9}$

5.M.3 Measure to the nearest centimeter

5.M.6 Determine the tool and technique to measure with an appropriate level of precision: lengths and angles

5.M.11 Justify the reasonableness of estimates

5.PS.10 Work in collaboration with others to solve problems
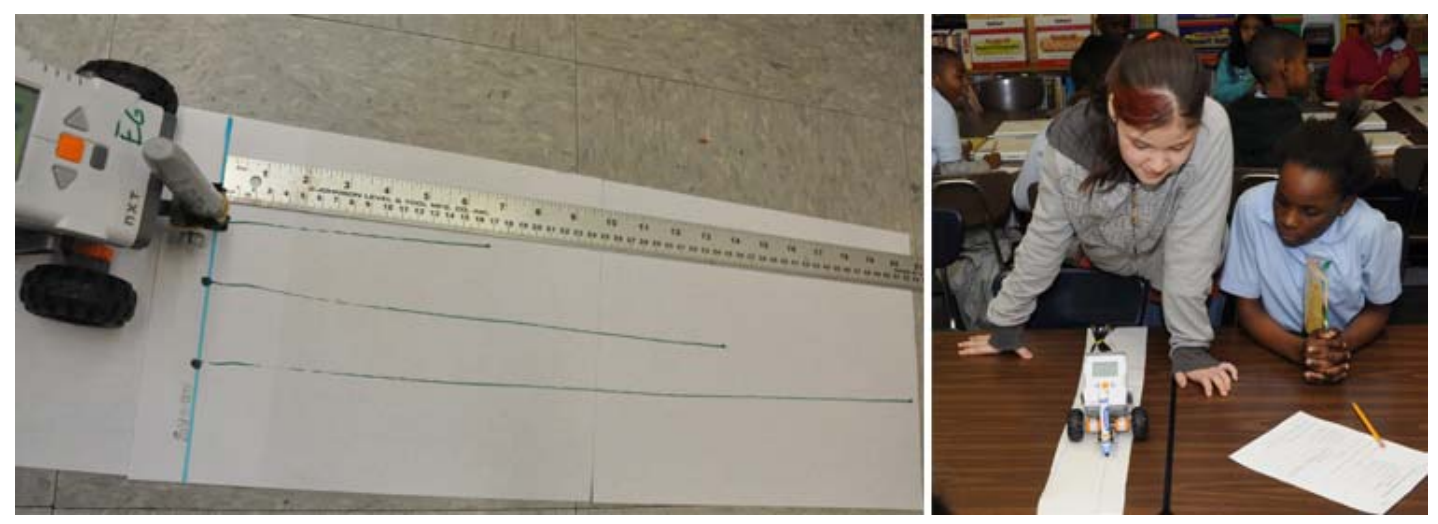

Figure 1: Activity setup for the "About Accuracy and Approximation" lesson (left) and students investigating the accuracy of their measurements with LEGO robots (right).

For each group in the classroom, a robot was built and fitted with an attachment that enabled the robot to hold a marker. A key feature of this setup was the robot's ability to draw a straight line when the wheels of the robot completed a specified number of rotations. Specifically, the robot was pre-programmed to move forward by one wheel rotation and draw a line, and two wheel rotations to draw a second, longer line. Students were given the values of the predicted distance the robot would travel with one and two wheel rotations. These values were obtained prior to the lesson by the Fellows using the circumference of the wheel and the number of specified rotations. Next, a robot with a marker attached was placed on a large sheet of paper and commanded to move forward with one complete rotation of its wheel, and in the process drew a line on the paper. Students measured the length of the drawn line and compared their measurements to the predicted length of the line. This procedure was repeated with two rotations of the robot's wheels. Students were asked to record, organize, and approximate their data in a datasheet (see Figure 2).

\subsection{Assessment for the Lesson on Accuracy and Approximation}

To assess the effectiveness of the lesson, 20 fourth grade and 25 fifth grade students in two math classrooms of a Central Brooklyn elementary school were introduced to the experimental setup. Figure 3 summarizes students' responses to pre- and post-surveys questions related to lesson content, connections between robotics and math, and applications of math in everyday life. The results of Figure 3 were obtained by evaluating students' responses based on 
the rubric in Table III. In addition, the Table offers exemplary responses that were considered "correct, clear, or positive" or "incorrect, unclear, or negative."

\begin{tabular}{|c|c|c|c|}
\hline Measure and Calculate & $\begin{array}{c}\text { In centimeters } \\
(\mathrm{cm})\end{array}$ & $\begin{array}{l}\text { Round up to the nearest } \\
\text { whole number }(\mathrm{cm})\end{array}$ & $\begin{array}{l}\text { Round down to the nearest } \\
\text { whole number }(\mathrm{cm})\end{array}$ \\
\hline Predicted length of the line & 35.4 & 36 & 35 \\
\hline Measured length of the line & 3 & 33 & 3 \\
\hline Measured - & 3.2 & 3 & \\
\hline
\end{tabular}

Figure 2: Table used to record data during the "About Accuracy and Approximation" lesson. The calculations and measurement were done by a $4^{\text {th }}$ grade student at a Central Brooklyn elementary school.

Table III: Categorization of students' responses in Figure 3 to evaluation question for "About Accuracy and Approximation" lesson.

\begin{tabular}{|c|c|c|}
\hline Assessment questions & $\begin{array}{c}\text { Correct/Clear/Positive } \\
\text { Response }\end{array}$ & $\begin{array}{c}\text { Incorrect/Unclear/Negative } \\
\text { Response }\end{array}$ \\
\hline $\begin{array}{l}\text { Q1. Round a number } \\
\text { to the nearest integer }\end{array}$ & $\begin{array}{l}\text { Student rounds a given number } \\
\text { correctly. }\end{array}$ & $\begin{array}{l}\text { Student rounds a given number } \\
\text { incorrectly. }\end{array}$ \\
\hline $\begin{array}{l}\text { Q2. Give an example } \\
\text { of an accurate } \\
\text { machine }\end{array}$ & $\begin{array}{l}\text { Student provides a clear example } \\
\text { of a computational or } \\
\text { mechanical machine. For } \\
\text { example: "computer," "washing } \\
\text { machine," or "microwave." }\end{array}$ & $\begin{array}{l}\text { Student provides an unclear } \\
\text { example of a computational or } \\
\text { mechanical machine. For example } \\
\text { "length," "I don't know," or } \\
\text { "pencil." }\end{array}$ \\
\hline $\begin{array}{l}\text { Q3. How are robots } \\
\text { and math related? }\end{array}$ & $\begin{array}{l}\text { Student describes an application } \\
\text { of math and robotics in } \\
\text { education, design, construction, } \\
\text { or programming For example: } \\
\text { "you have to know math when } \\
\text { you are making a robot," "robots } \\
\text { use math," or "robots can } \\
\text { measure." }\end{array}$ & $\begin{array}{l}\text { Student doesn't relate or provide } \\
\text { a clear understanding of the } \\
\text { question. For example: "I don't } \\
\text { know," "because they are both } \\
\text { machines," or "because math and } \\
\text { robots are fun." }\end{array}$ \\
\hline $\begin{array}{l}\text { Q4. Where can you } \\
\text { use mathematics? }\end{array}$ & $\begin{array}{l}\text { Student describes math related } \\
\text { activities or places outside or } \\
\text { inside the classroom. For } \\
\text { example: "playing board } \\
\text { games," or "when I count } \\
\text { change." }\end{array}$ & $\begin{array}{l}\text { Student provides } \\
\text { description that pertains to the } \\
\text { assessment question. For } \\
\text { example: "everywhere," or "side } \\
\text { walk." }\end{array}$ \\
\hline
\end{tabular}


Q1. Round to the nearest integer - Pre-activity $\quad$ Post-activity

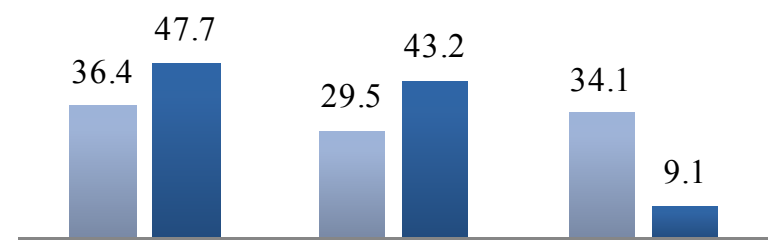

Clear/positive Unclear/negative No response response response

(a)

Q3. How are robots and math related?

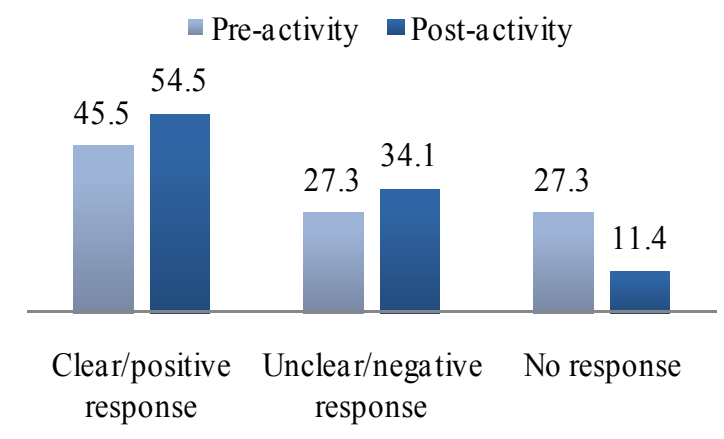

(c)
Q2. Give an example of accurate machine

$$
\text { - Pre-activity } \quad \text { Post-activity }
$$

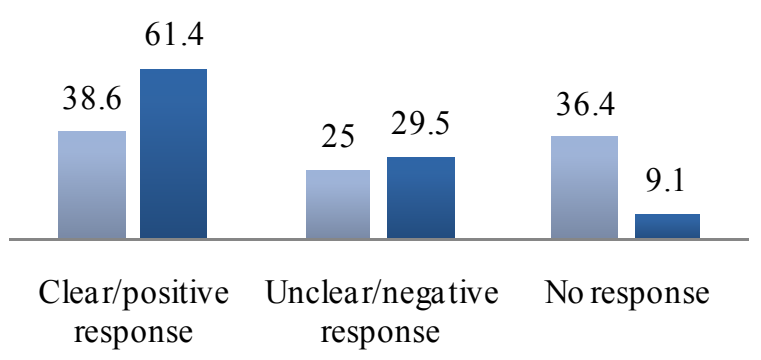

(b)

Q4. Where can you use mathematics?

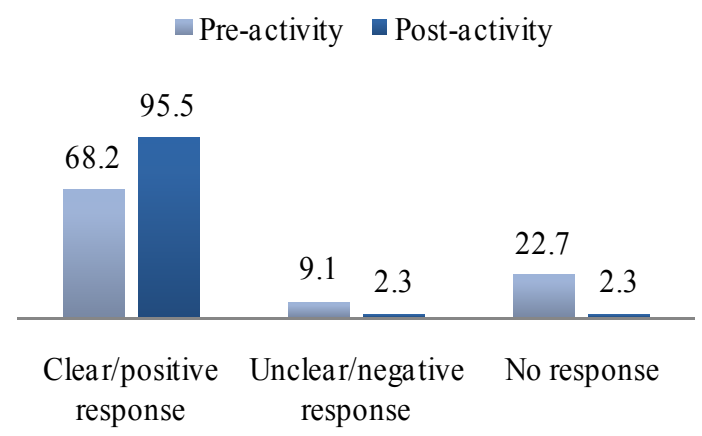

(d)

Figure 3: Students' responses to pre- and post-survey questions for the "About Accuracy and Approximation" activity. Responses to content questions: (a), (b) and views on robotics (c) and mathematics (d).

To measure the lesson effectiveness, a paired difference $t$-test for dependent samples was conducted. The results for the test are shown in Table IV. For a $p$ value of $<0.0025$ and $<0.001$, results for questions Q2 and Q4, respectively, reveal statistically significant improvement. However, for questions Q1 and Q3, the results do not provide evidence of statistically significant improvement, i.e., they are not significant (n.s.). Note that the bar charts of Figure 3(a), 3(c), show that both correct and incorrect responses to Q1 and Q3 increased in the post-lesson evaluation due to the participation of students who provided no response in pre-lesson evaluation. 
Table IV: Results of paired difference $t$-test for "About Accuracy and Approximation" lesson, $n$ denotes the number of samples.

\begin{tabular}{lrrrrrr}
\hline \multicolumn{1}{c}{ Assessment questions } & $\boldsymbol{n}$ & $\begin{array}{c}\text { Mean } \\
\text { difference }\end{array}$ & $\begin{array}{r}\text { Standard } \\
\text { deviation }\end{array}$ & $\boldsymbol{t}_{\text {calculated }}$ & $\boldsymbol{p}$ Value \\
\hline Q1. Round to the nearest integer & 45 & 11.111 & 71.421 & 1.044 & n.s. \\
Q2. Give an example of an accurate machine & 45 & 25.556 & 58.019 & 2.955 & $<0.0025$ \\
Q3. How are robots and math related? & 45 & 5.556 & 43.265 & 0.863 & n.s. \\
Q4. Where can you use mathematics? & 45 & 16.111 & 30.224 & 3.576 & $<0.001$ \\
\hline
\end{tabular}

\section{Lesson on "Pi"}

The irrational number Pi (represented by $\pi=3.1415926 \ldots$ ) is a remarkable constant that is found in many STEM disciplines. For example, $\pi$ is found in numerous formulae arising in mathematics, physics, chemistry, and engineering, making it one of the most important mathematical constants. The activity "Pi - What is it?" was developed to promote conceptual understanding of the irrational properties of $\pi$ and its applications in geometry to middle school students. One of the objectives of the activity was to create an environment in which students could feel like researchers seeking to establish an approximate value of $\pi$. Students were asked to work in teams to discover that $\pi$ is a constant that applies to all circles. The lesson addresses NYS Learning Standards for Mathematics shown in the Table V, and requires one to two 45minute class periods to complete. A LEGO NXT robot with a pen holder was built for each group, identical to the robot used for the "About Accuracy and Approximation" lesson (see Figure 4).

Table V: NYS Learning Standards addressed in "Pi - What is it?" lesson."

6.CN.6 Recognize and provide examples of the presence of mathematics in their daily lives

6.G.9 Understand the relationship between the circumference and the diameter of a circle

6.N.6 Understand the concept of ratio

6.R.1 Use physical objects, drawings, charts, tables, graphs, symbols, equations, or objects created using technology as representations

Each student team used a pre-programmed LEGO robot that travelled in a circle to draw different sized circles. Next, a large sheet of paper was taped to the floor and the robot was placed on it and commanded to perform a full circular motion. This caused the robot to physically draw a circle as the marker tip touched the paper. Students measured the diameter of the circle using a ruler and the circumference using a length of yarn. Finally, using the measured values, students divided the circumference by the diameter and showed that the result was the constant $\pi$ (see Figure 4). Students performed multiple runs of the experiment by altering the 
robot program to draw circles of different sizes. This exercise enabled the students to observe that the value of $\pi$ can be obtained from a circle of an arbitrary diameter.
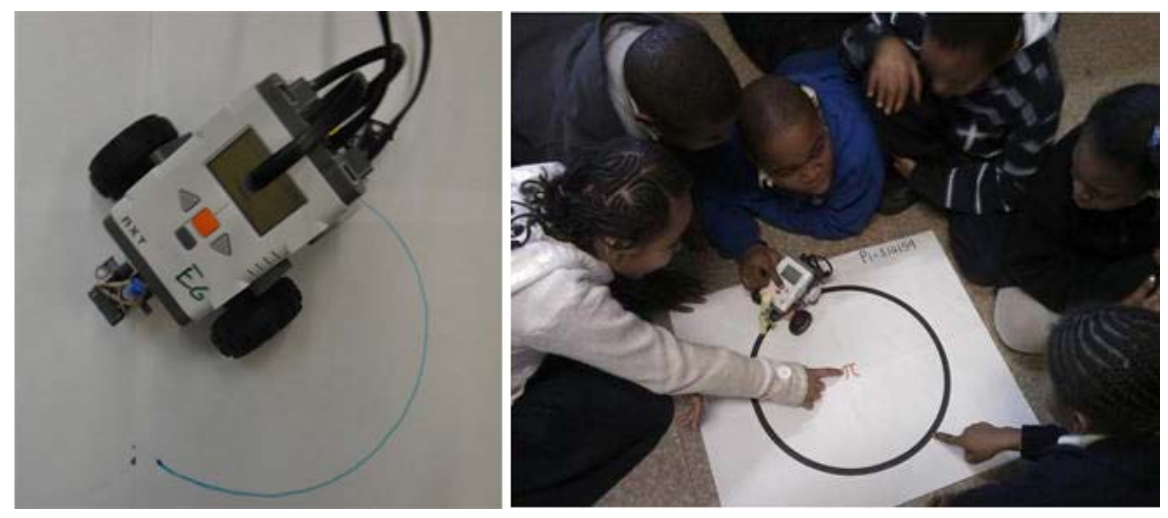

Figure 4: Activity set up for the "Pi - What is it?" lesson (left) and students discussing how to calculate distance as the robot travels along a circular path (right).

\subsection{Assessment for the Lesson on "Pi"}

To assess the effectiveness of the lesson, 47 sixth grade students in a math classroom of a Central Brooklyn middle school were introduced to the experimental setup. The activity was intended to preview the usefulness and application of $\pi$ prior to its formal introduction in the classroom. As part of the curriculum, the students were expected to learn the properties of $\pi$ and its application in geometrical formulae such as area and circumference of the circle. Figure 5 provides a sample datasheet that was completed by a student who participated in the activity. Figure 6 summarizes students' responses to pre- and post-surveys questions related to lesson content, usefulness of robotics as an educational tool, and applications of math in everyday life. The results of Figure 6 were obtained by evaluating students' responses based on the rubric in Table VI. In addition, the Table offers exemplary responses that were considered "correct, clear, or positive" or "incorrect, unclear, or negative." To measure the lesson effectiveness, a paired difference $t$-test for dependent samples was conducted. The results for the test are shown in Table VII. For a $p$ value of $<0.001(\mathrm{Q} 1-\mathrm{Q} 3)$ and $<0.025(\mathrm{Q} 4)$, results show that there is a statistically significant improvement from pre- to post-lesson assessment.

\begin{tabular}{|c|c|c|c|}
\hline & Circumference, $\mathrm{cm}$ & Diameter, $\mathrm{cm}$ & $c / d$ \\
\hline Circle \#1 & 41 & 13 & 3,15 \\
\hline Circle \#2 & 61 & 18 & 3.38 \\
\hline
\end{tabular}

Figure 5: Table used to record data during the "Pi - What is it?" lesson. The calculations and measurement were done by a $6^{\text {th }}$ grade student at a Central Brooklyn middle school. 
Table VI: Categorization of students' responses in Figure 6 to evaluation question for "Pi What is it?" lesson.

\begin{tabular}{|c|c|c|}
\hline Assessment questions & $\begin{array}{c}\text { Correct/Clear/Positive } \\
\text { Response }\end{array}$ & $\begin{array}{c}\text { Incorrect/Unclear/Negative } \\
\text { Response }\end{array}$ \\
\hline $\begin{array}{l}\text { Q1. What is numerical } \\
\text { value of } \pi \text { ? }\end{array}$ & $\begin{array}{l}\text { Student provides an answer } \pi= \\
3.14 \text { or } \pi \approx 3.14 \text {. }\end{array}$ & $\begin{array}{l}\text { Student gives answer that } \\
\text { differs from } \pi=3.14 \text { or } \pi \approx \\
3.14 \text {. }\end{array}$ \\
\hline $\begin{array}{l}\text { Q2. What does the ratio of } \\
\text { circumference to diameter, } \\
\text { C/d, equal to? }\end{array}$ & $\begin{array}{l}\text { Student provides an answer } \pi \text { or } \\
3.14 \text {. }\end{array}$ & $\begin{array}{l}\text { Student provides an answer } \\
\text { that differs from } \pi \text { or } 3.14 \text {. }\end{array}$ \\
\hline $\begin{array}{l}\text { Q3. How can robots help } \\
\text { you learn math? }\end{array}$ & $\begin{array}{l}\text { Student describes an experience } \\
\text { with robot that can help him/her } \\
\text { to learn math better. For } \\
\text { example: "showing examples } \\
\text { and helping understand } \\
\text { problems," or "creating them } \\
\text { will require math." }\end{array}$ & $\begin{array}{l}\text { Student doesn't relate or } \\
\text { provide a clear } \\
\text { understanding of the } \\
\text { question. For example: "I'm } \\
\text { not sure," or "geometry, } \\
\text { science and physics." }\end{array}$ \\
\hline $\begin{array}{l}\text { Q4. Where can you use } \\
\text { mathematics? }\end{array}$ & $\begin{array}{l}\text { Student describes activities: } \\
\text { making change "while buying } \\
\text { groceries," "shopping at a mall," } \\
\text { "following a cookbook to cook," } \\
\text { or "measuring space at home } \\
\text { during remodeling." }\end{array}$ & $\begin{array}{l}\text { Student doesn't provide a } \\
\text { response or description that } \\
\text { pertains to the assessment } \\
\text { question. For example: } \\
\text { "nowhere," "everywhere," or } \\
\text { "in your kitchen." }\end{array}$ \\
\hline
\end{tabular}

Q1. What is the numerical value of Pi?

- Pre-activity $\square$ Post-activity

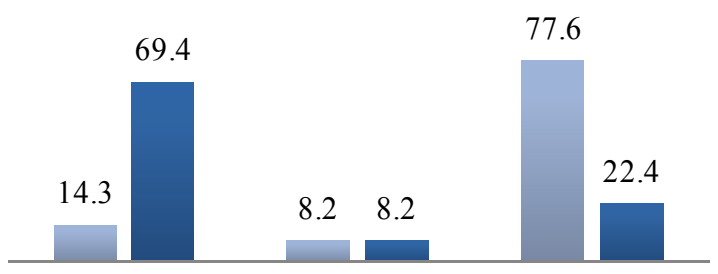

Correct response Incorrect response No response

(a)
Q2. What does the ratio $\mathrm{C} / \mathrm{d}$ equal to?

- Pre-activity $\square$ Post-activity

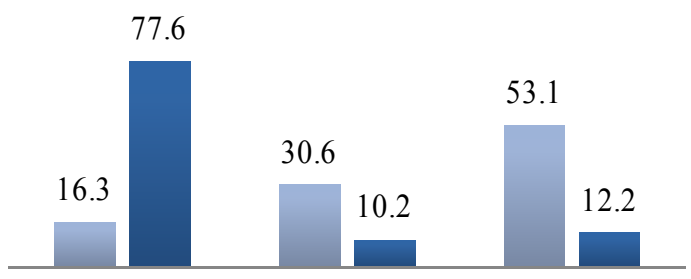

Correct response Incorrect response No response 
Q3. Can robots help you leam math?

- Pre-activity $\quad$ Post-activity

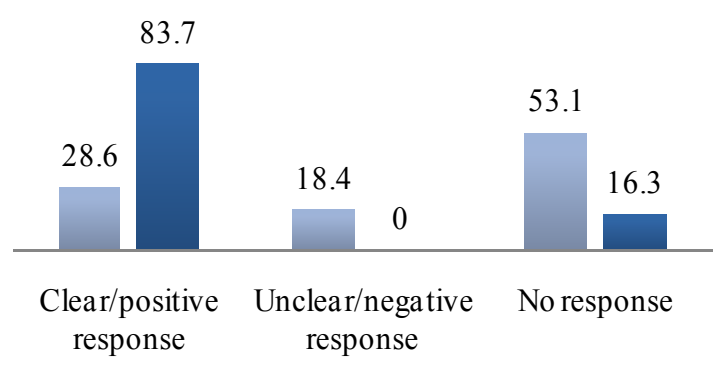

(c)
Q4. Where can you use mathematics?

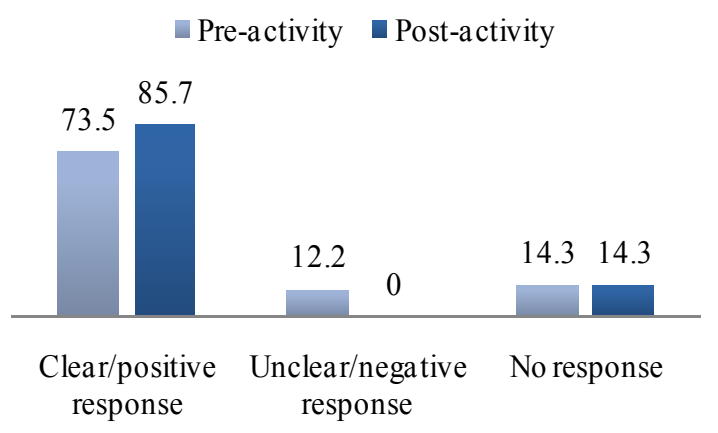

(d)

Figure 6: Students' responses to pre- and post-survey questions for the "Pi - What is it?" activity. Responses to content questions: (a), (b) and views on robotics (c) and mathematics (d).

Table VII: Results of paired difference $t$-test for "Pi - What is it?" lesson.

\begin{tabular}{lccccc}
\hline \multicolumn{1}{c}{ Assessment questions } & $\boldsymbol{n}$ & $\begin{array}{c}\text { Mean } \\
\text { difference }\end{array}$ & $\begin{array}{c}\text { Standard } \\
\text { deviation }\end{array}$ & $\mathbf{t}_{\text {calculated }}$ & $\begin{array}{c}\boldsymbol{p} \\
\text { Value }\end{array}$ \\
\hline Q1. What is the numerical value of Pi? & 47 & 57.447 & 49.977 & 7.880 & $<0.001$ \\
Q2. What does the ratio C/d equal to? & 47 & 61.702 & 49.137 & 8.609 & $<0.001$ \\
Q3. How can robots help you learn math? & 47 & 22.340 & 41.779 & 3.666 & $<0.001$ \\
Q4. Where can you use mathematics? & 47 & 12.234 & 34.919 & 2.402 & $<0.025$ \\
\hline
\end{tabular}

\section{Lesson on Means, Modes, and Medians}

One of the primary and necessary skills in all STEM fields is the acquisition of data and its analysis. Pursuant to the demand of these analytical skills and to address NYS Learning Standards for Mathematics shown in the Table VIII, a lesson involving empirical data collection and analysis was developed. Entitled "Means, Modes, and Medians," the objective of this handson lesson was for students to collect and study the data from the periodic motion of an oscillating spring-mass system using LEGO sensors. The experimental setup consisted of a LEGO NXT brick, LEGO ultrasonic and touch sensors, RobotC or LEGO Mindstorms software, a bungee cord, a weight, a clamp-stand, and a cardboard platform (see Figure 7). The curriculum level of the lesson is suitable for middle and high school students and requires two consecutive 45minute class periods. Prior to the lesson, students were divided into teams and were given a preevaluation worksheet as well as an experimental procedure manual. In the worksheet, students recalled definitions and formulae of the aforementioned statistical quantities and solved supporting math problems. In addition, the students were asked to fill out a survey inquiring about their opinions on the importance of mathematics and robotics. 
Table VIII: NYS Learning Standards addressed in "Means, Modes and Medians" lesson.9

\begin{tabular}{ll}
\hline A.CN.7 & $\begin{array}{l}\text { Recognize and apply mathematical ideas to problem situations that develop outside } \\
\text { of mathematics }\end{array}$ \\
A.R.1 & $\begin{array}{l}\text { Use physical objects, diagrams, charts, tables, graphs, symbols, equations, or objects } \\
\text { created using technology as representations of mathematical concepts }\end{array}$ \\
A.S.1 & $\begin{array}{l}\text { Categorize data as qualitative or quantitative } \\
\text { A.S.4 }\end{array}$ \\
& $\begin{array}{l}\text { Compare and contrast the appropriateness of different measures of central tendency } \\
\text { for a given data set }\end{array}$ \\
\hline
\end{tabular}

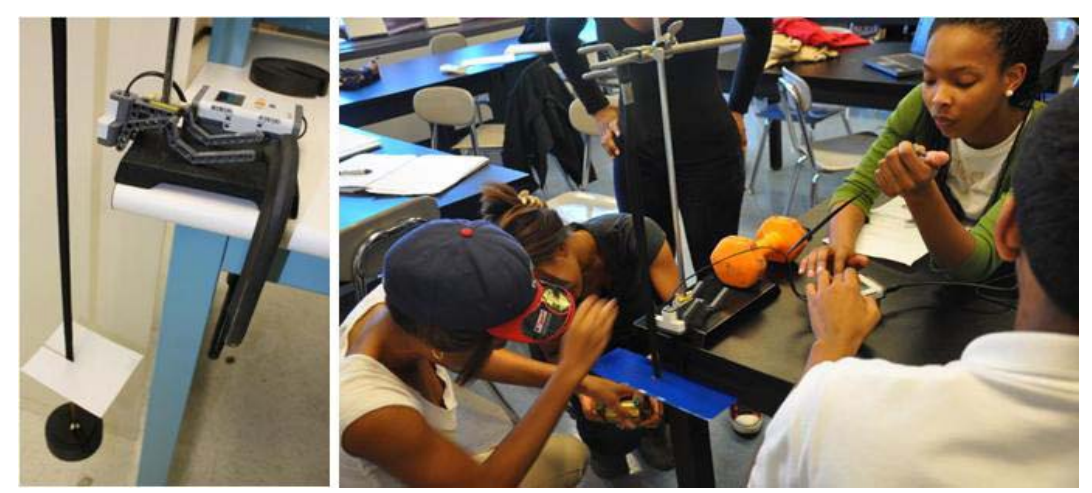

Figure 7: Activity setup for the "Means, Modes and Medians" lesson (left) and students preparing to collect oscillation data for a bungee cord with $100 \mathrm{~g}$ mass (right)

During the lesson, the students were first given a presentation and a demonstration of the setup. Next, the students were asked to perform the experiment by following the step-by-step procedure of the experiment manual. The lesson and the experiment were designed and set up as follows. The bungee cord was suspended from the clamp-stand with a 100 gram mass and a $25 \mathrm{~cm} \times 10 \mathrm{~cm}$ cardboard platform rigidly attached to the inelastic part of the cord (see Figure 7 ). The ultrasonic sensor was placed on the base of the clamp-stand and above the platform to measure its distance from the oscillating platform. The students executed a preloaded program on the NXT brick to measure the displacements of the platform while the bungee cord oscillated. The program was terminated once the system rested at its equilibrium. To collect the data, the NXT brick was preloaded with a user-friendly RobotC or Mindstorms data logging program that allowed students to begin and terminate data collection by activating the touch sensor. In addition, the students learned to access the data stored in the NXT brick using the LEGO interface software and save it as a spreadsheet. Before the quantitative analysis, the empirical data had to be visually analyzed for occurrence of outliers. The outliers arose due to sideways swaying of the platform, causing it to move out of the field of view of the ultrasonic sensor and resulting in erroneous data corresponding to the sensor's distance from the floor. If the data was considered erroneous by the students, the experiment was repeated. After the data was obtained in spreadsheet format, the students were asked to complete an analysis worksheet and a postevaluation survey. Prior to performing data analysis, the students were asked to pick two sets of 
consecutive numbers from the collected data. The two sets consisted of five and ten elements, respectively (see Figure 8). In a worksheet, the students were asked to determine the mean, mode, and median for both sets of data and compare the outcomes using percent difference.

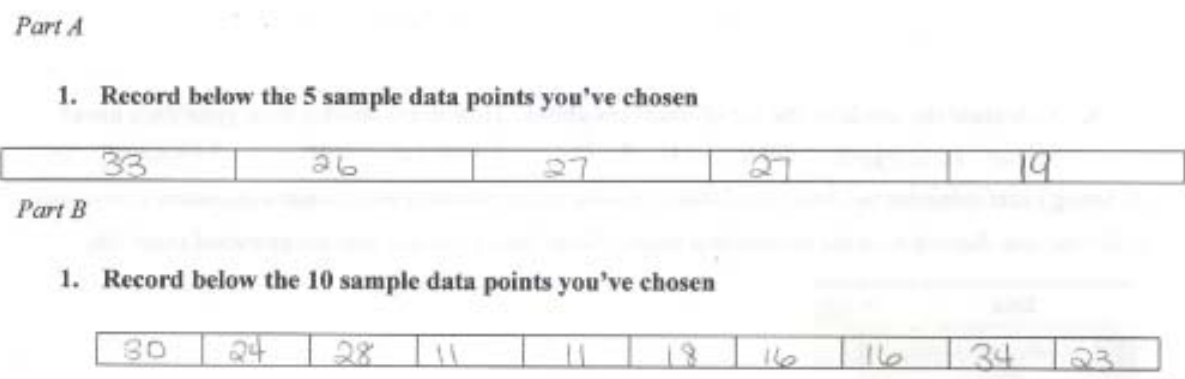

Figure 8: Tables used to record data during the "Means, Modes and Medians" lesson. The data was recorded by a $9^{\text {th }}$ grade student at a Central Brooklyn high school.

\subsection{Assessment for the Lesson on Means, Modes, and Medians}

To assess the effectiveness of the lesson, 46 ninth grade students in a math classroom of a Central Brooklyn high school were introduced to the experimental setup. The lesson was indented to review students' knowledge of basic statistics as part of the preparation for the Regents exam. The students had been previously introduced to the statistical quantities such as mean, mode, median, however, they had limited knowledge of percent difference between two quantities. In addition, some students needed extra review on finding median values in sets with even and odd number of elements. Figure 9 summarizes students' responses to pre- and postsurveys questions related to lesson content, usefulness of robotics as an educational tool, and applications of math in everyday life. The results of Figure 9 were obtained by evaluating students' responses based on the rubric in Table IX, which also offers exemplary responses that were considered "correct, clear, or positive" or "incorrect, unclear, or negative." To measure the lesson effectiveness, a paired difference $t$-test for dependent samples was conducted. The results for the test are shown in Table X. For a $p$ value of $<0.05$ and $<0.001$, results for questions Q2 and Q3, respectively, reveal statistically significant improvement. However, for questions Q1 and Q4, the results do not provide evidence of statistically significant improvement. Note that this lesson was conducted as a review, thus the results have not shown a significant improvement in every aspect of the survey. 
Table IX: Categorization of students' responses in Figure 9 to evaluation question for "Means, Modes and Medians" lesson.

\begin{tabular}{|c|c|c|}
\hline Assessment questions & $\begin{array}{c}\text { Correct/Clear/Positive } \\
\text { Response }\end{array}$ & $\begin{array}{c}\text { Incorrect/Unclear/Negative } \\
\text { Response }\end{array}$ \\
\hline you find the & $\begin{array}{l}\text { Student provides a formula or } \\
\text { an explanation how to find } \\
\text { median. }\end{array}$ & $\begin{array}{l}\text { Student doesn't know the } \\
\text { formula or method to determine } \\
\text { the median. }\end{array}$ \\
\hline you find the & $\begin{array}{l}\text { Student provides a formula or } \\
\text { an explicit statement describing } \\
\text { the method of finding the } \\
\text { average. }\end{array}$ & $\begin{array}{l}\text { Student doesn't know the } \\
\text { formula or method to find } \\
\text { average. }\end{array}$ \\
\hline $\begin{array}{l}\text { obots help } \\
\text { ? }\end{array}$ & $\begin{array}{l}\text { Student describes an experience } \\
\text { with robot that can help him/her } \\
\text { to learn math better. For } \\
\text { example: "they can be used to } \\
\text { measure and record data," } \\
\text { "serve as calculators," or "write } \\
\text { on the board." }\end{array}$ & $\begin{array}{l}\text { Student doesn't relate or provide } \\
\text { a clear understanding of the } \\
\text { question. For example: "not } \\
\text { really sure," or "I really don't } \\
\text { understand." }\end{array}$ \\
\hline $\begin{array}{l}\text { Q4. Where can you us } \\
\text { mathematics? }\end{array}$ & $\begin{array}{l}\text { Student describes a profession } \\
\text { or activity that utilizes math. } \\
\text { For example: "engineering," } \\
\text { "medicine," "using money," } \\
\text { "tell time," or "coding." }\end{array}$ & $\begin{array}{l}\text { Student doesn't provide a } \\
\text { response or description that } \\
\text { pertains to the assessment } \\
\text { question. For example: } \\
\text { "everywhere." }\end{array}$ \\
\hline
\end{tabular}

Q1. How do you find the median?

$\square$ Pre-activity $\square$ Post-activity

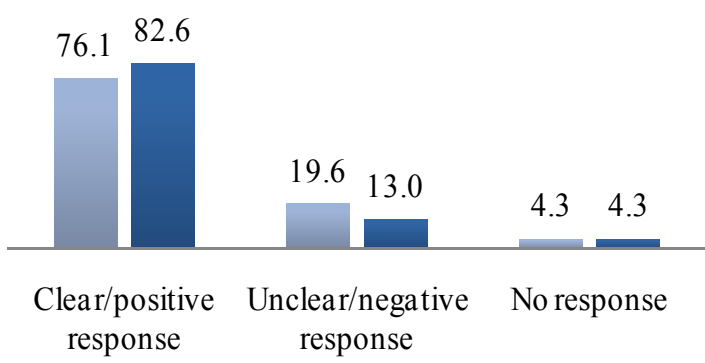

(a)
Q2. How do you find the average?

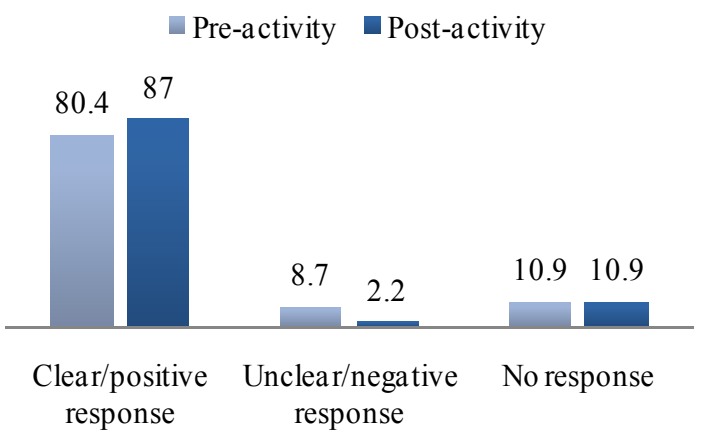

(b) 
Q3. How can robots help you learn math?

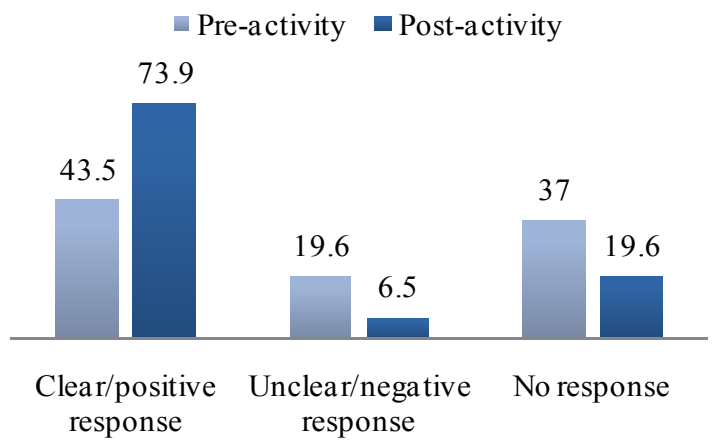

(c)
Q4. Where can you use mathematics?

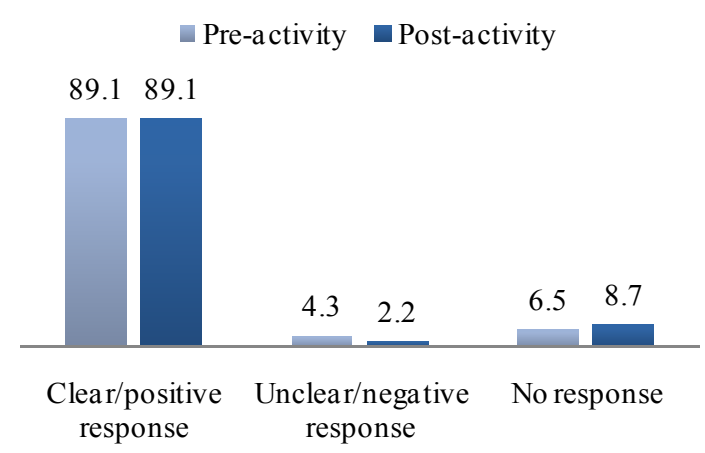

(d)

Figure 9: Students' responses to pre- and post-survey questions for the "Means, Modes and Medians" activity. Responses to content questions: (a), (b) and views on robotics (c) and mathematics (d).

Table X: Results of paired difference $t$-test for "Means, Modes, and Medians" lesson.

\begin{tabular}{llrrrrr}
\hline \multicolumn{1}{c}{ Assessment questions } & $\boldsymbol{n}$ & $\begin{array}{c}\text { Mean } \\
\text { difference }\end{array}$ & $\begin{array}{r}\text { Standard } \\
\text { deviation }\end{array}$ & $\boldsymbol{t}_{\text {calculated }}$ & $\begin{array}{c}\boldsymbol{p} \\
\text { Value }\end{array}$ \\
\hline Q1. How do you find the median? & 46 & 1.630 & 58.784 & 0.188 & n.s. \\
Q2. How do you find the average? & 46 & 11.957 & 42.733 & 1.898 & $<0.05$ \\
Q3. How can robots help you learn math? & 46 & 22.826 & 44.355 & 3.490 & $<0.001$ \\
Q4. Where can you use mathematics? & 46 & -4.891 & 32.753 & -1.013 & n.s. \\
\hline
\end{tabular}

\section{Conclusions}

To promote engagement and learning in K-12 math classrooms and assist with the development of better understanding of abstract mathematical material, lessons incorporating LEGO-based activities were introduced to students in Central Brooklyn schools. This paper presented three illustrative examples of hands-on lessons that proved useful in enhancing students' comprehension of the underlying math concepts and boosting their interest in the subject matter. The evaluations of all three lessons showed that students improved their conceptual understanding of the lesson content after conducting the activity. Moreover, students showed an increase in interest and motivation to learn math through team activities. On-site observations and post-evaluations have demonstrated a positive inclination towards working with robotics tools and computational software. These activities exposed students to real-world applications of mathematics outside of classrooms, such as measuring distance with an ultrasonic sensor. These lessons incorporated LEGO robots, sensors, and computing platforms to conduct experimental investigations and acquire data. Such lessons can be useful to allow students to 
connect science and math lessons and develop an interdisciplinary understanding. Future plans include dissemination of these and other LEGO-based math lessons, developed by our Fellowteacher teams, to all schools in our GK-12 Fellows program and to a wider audience of teachers through annual workshops and through a web repository of lessons.

\section{Acknowledgements}

This work is supported in part by the GK-12 Fellows Program of National Science Foundation under grant DGE-0741714: Applying Mechatronics to Promote Science (AMPS). In addition, it is supported in part by the Central Brooklyn STEM Initiative (CBSI), which is funded by the Black Male Donor Collaborative, Brooklyn Community Foundation, J.P. Morgan Chase Foundation, Motorola Innovation Generation Grant, NY Space Grant Consortium, Xerox Foundation, and White Cedar Fund. The authors thank the following K-12 teachers for careful review of lessons and assessment instruments and participation: Michael Smith, elementary school teacher from PS 256; Kesha Townsel, elementary school teacher from PS 5; Menaka Jeypalah, middle school teacher from Urban Assembly Institute of Math \& Science for Young Women; Noam Pillischer, high school teacher from Urban Assembly Institute of Math \& Science for Young Women; and Imani Fischer, high school teacher from Benjamin Banneker High School. The authors also thank the following GK-12 Fellows: Carole Chen for developing "PiWhat is it?" lesson; and Jennifer Haghpanah, Nicole Abaid and Ursula Koniges for their help in conducting the lessons.

\section{References}

1. A. Melchior, T. Cutter, F. Cohen. F., Evaluation of First LEGO League Underserved Initiative. Executive summary, Brandeis University, 2005.

2. D. Burghardt and M. Hacker, "Engineering Professional Development," National Symposium on Professional Development for Engineering and Technology Education, Dallas, Texas, February 11-13, 2007. Available online at: http://conferences.illinoisstate.edu/NSA/papers/BurghardtHacker.pdf.

3. G. Orsak, D.C. Munson, A. Weil, M. Conner, and D. Rummel, "High-tech Engineering for High School: It's Time!” IEEE Signal Processing Magazine, 21(1), 103-108, 2004.

4. W. Church, T. Ford, N. Perova, and C. Rogers, "Physics with Robotics Using LEGO MINDSTORMS in High School Education," Association for the Advancement of Artificial Intelligence Spring Symposium, Palo Alto, CA, 2010 Available online at: http://www.aaai.org/ocs/index.php/SSS/SSS10/paper/viewFile/1062/1398.

5. H. Mukai and N. McGregor, "Robot Control Instruction for Eighth Graders," IEEE Control Systems Magazine, 24(5): 20-23, 2005.

6. R. Shoop, Robotics Educator 2.5 Curriculum Guide, Robotics Academy. Pittsburg, PA: Carnegie Mellon University. Available online at: http://www.education.rec.ri.cmu.edu/roboticscurriculum/ curriculum/curriculum_2.5.pdf.

7. S.J. Norton, C.J. McRobbie, and I.S. Ginns, "Problem Solving in a Middle School Robotics Design Classroom," Research in Science Education, 37(3): 261-277, 2007. 
8. E. Cejka and C. Rogers, "Inservice Teachers and the Engineering Design Process," Proc. Amer. Soc. Eng. Ed., Portland, OR, 2005

9. Online: http://www.p12.nysed.gov/ciai/mst/math/standards/core.html, New York State Education Department, Mathematics Core Curriculum, 2005.

10. Online: http://gk12.poly.edu/amps-cbri/, website of the Applying Mechatronics to Promote Science (AMPS)/Central Brooklyn Robotics Initiative (CBRI) Project.

11. D. Sheskin, Handbook of Parametric and Nonparametric Statistical Procedures, Chapman \& Hall/CRC Press, Boca Raton, FL, 2007. 